\title{
A EDUCAÇÃO A DISTÂNCIA NA UNIVERSIDADE ESTADUAL DE MATO GROSSO DO SUL
}

\author{
DISTANCE EDUCATION IN MATO GROSSO DO SUL STATE \\ UNIVERSITY
}

Glaucia Gabriel SASS ${ }^{1}$

Maria da Silva PEIXOTO ${ }^{2}$

\section{Resumo}

As transformações ocorridas na sociedade e tecnologias afetam as Instituições de Ensino Superior, entre elas estão a forma de relacionamento entre as pessoas e a maneira de acesso aos mais diversos conteúdos, seja educativo ou para entretenimento. O objetivo desse artigo é apresentar a trajetória da modalidade de ensino a distância na Universidade Estadual de Mato Grosso do Sul. A metodologia foi pautada no relato de experiência baseado numa análise documental, foram levantados os dados para descrever as ações desenvolvidas pela administração da instituição. Foi um trabalho de resgate das ações e resultados da EaD/UEMS. Nesse levantamento foi possível identificar a importância da Universidade Aberta do Brasil no fomento da modalidade de ensino a distâncias nas Instituições de Ensino Superior. Suas atividades foram fundamentais para capacitar os servidores da Universidade e o fomento permitiu a implantação da modalidade. O processo iniciado pela Universidade Aberta do Brasil está em um momento de fragilidade, as Instituições de Ensino Superior precisarão assumir algumas responsabilidades para não deixar que se perca tudo que foi construído.

Palavras-chave: Educação a Distância. Processo de implantação. Universidade Estadual de Mato Grosso do Sul - UEMS. Universidade Aberta do Brasil.

\begin{abstract}
The occurred transformations in the society and technologies affect the institutions of university education, between them there is the form of relationship between the people and the way of access to the most several contents, whether educational or for entertainment. The objective of that article is to present the path of the modality of the distance education in the State University of Mato Grosso do Sul. The methodology was ruled on the report of experience based on a documentary analysis, were raised the data to describe the actions developed from the administration of the institution. It was a good work of rescue the actions and results of the $\mathrm{EaD} / \mathrm{UEMS}$. In that survey it was possible to identify the importance of the Open University of Brazil in the fomentation of the modality on the distance education in the higher education institutions. Your activities were fundamental to empower servants of the university and the foment allowed the implementation of the modality. The process initiated by the Open
\end{abstract}

\footnotetext{
${ }^{1}$ Universidade Estadual de Mato Grosso do Sul - glaucia@comp.uems.br

${ }^{2}$ Universidade Estadual de Mato Grosso do Sul - mpeixoto@uems.br
} 


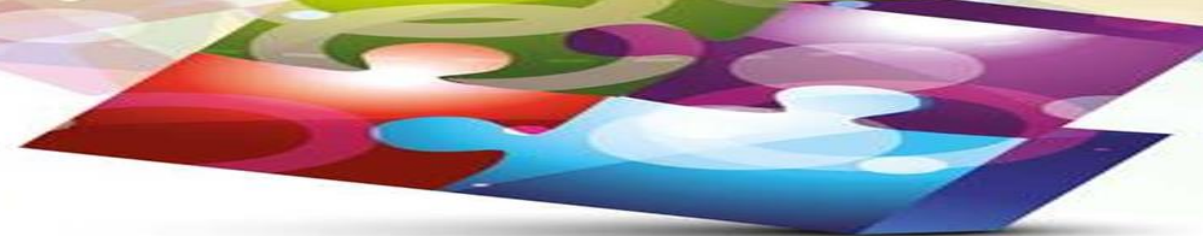

University of Brazil is in a moment of fragility, the higher education institutions will need to take over some responsibility not to lose everything that was built

Key word: Distance education. The implementation process. State University of Mato Grosso do Sul - UEMS. Open University of Brazil

\section{Introdução}

Os processos de ensino-aprendizagem têm sofrido transformações quanto as relações entre professores e alunos, além da disponibilização de recursos didáticos em novos formatos, como hipertextos e vídeos. A relação professor-aluno antes realizada em sala de aula física, na qual professor e aluno estão no mesmo local e ao mesmo tempo, agora se apresenta sem a necessidade deles estarem no mesmo local, no espaço e tempo. Essas transformações são resultado da modalidade de ensino a distância.

Nesse contexto as instituições de ensino tem buscado absorver essas transformações. No setor privado a expansão e crescimento do ensino na modalidade a distância tem sido muito mais rápido. A principal causa desse crescimento são os investimentos financeiros. No setor público o processo é sempre mais moroso, os recursos financeiros são limitados e a burocracia atrasa as ações. Um exemplo é o processo de criação de cursos em uma Instituição de Ensino Superior Pública, são tantas as instâncias para a elaboração ou alteração do projeto pedagógico, que o processo pode levar mais de um ano.

Mas, mesmo com as “dificuldades” para a implantação das mudanças dos processos de ensino aprendizagem as Instituições de Ensino Superior Públicas têm superado os obstáculos. Para apresentar esse cenário, o presente trabalho se propõe a trazer um histórico da Educação a Distância no âmbito da Universidade Estadual de Mato Grosso do Sul. Das primeiras ações com vistas à implantação da modalidade a distância na Universidade.

Este artigo tem por objetivo apresentar a trajetória de implantação da modalidade a distância na Universidade Estadual de Mato Grosso do Sul. Trata-se de um relato de experiência e de análise documental de ações tomadas pela UEMS no sentido de implantar a modalidade EaD na Instituição. Com isso, ressaltamos a importância da Universidade Aberta do Brasil neste no que se refere a fomento e capacitação de recursos humanos. Entretanto, com o passar do tempo e, considerando-se a conjuntura econômica em que se encontra a CAPES, as IES precisam assumir a responsabilidade pela continuidade das ações iniciadas pela UAB e dar prosseguimento com a institucionalização da modalidade internamente. 


\section{UMA BREVE HISTÓRIA DA UNIVERSIDADE ESTADUAL DE MATO GROSSO DO SUL}

A Universidade Estadual de Mato Grosso do Sul (UEMS) foi criada pelo Art. 190 da Constituição Estadual de 13 de junho de 1979, com sede em Dourados - MS (MATO GROSSO DO SUL, 1979). Sua instalação foi autorizada pela Lei Estadual n. 533, de 12 de março de 1985 (MATO GROSSO DO SUL, 1985). No entanto, apesar dos atos legais, a UEMS não foi implantada.

A Constituição Estadual de 5 de outubro de 1989 em seu artigo 48 - das Disposições Transitórias cria novamente a UEMS e ressalta que a instalação e funcionamento devem acontecer no início de 1992 (MATO GROSSO DO SUL, 1989). Entretanto, somente em 1993 o poder Executivo institui a UEMS pela Lei Estadual n. 1.461, de 20 de dezembro de 1993 e pelo Decreto Estadual n. 7,585, de 22 de dezembro de 1993. A partir desses dois últimos atos, foi realizado no primeiro semestre de 1994 o primeiro vestibular da UEMS, com início do ano letivo no segundo semestre de 1994. Passaram-se 15 anos desde o primeiro ato legal de criação em 1979 até o funcionamento efetivo da UEMS, em 1994.

Em 2019, a UEMS faz 25 anos de existência atendendo a sociedade e levando conhecimento e desenvolvimento às regiões onde se localizam as 15 Unidades Universitárias (UU): Dourados (sede), Aquidauana, Amambai, Cassilândia, Coxim, Glória de Dourados, Ivinhema, Jardim, Maracaju, Mundo Novo, Naviraí, Nova Andradina, Paranaíba, Ponta Porã e Campo Grande (criado em 2001), Figura 1.

Figura 1: UU distribuídas pelo estado de Mato Grosso do Sul. 


\section{MORIZONTES - REVISTA DE EDUCAÇÃO}
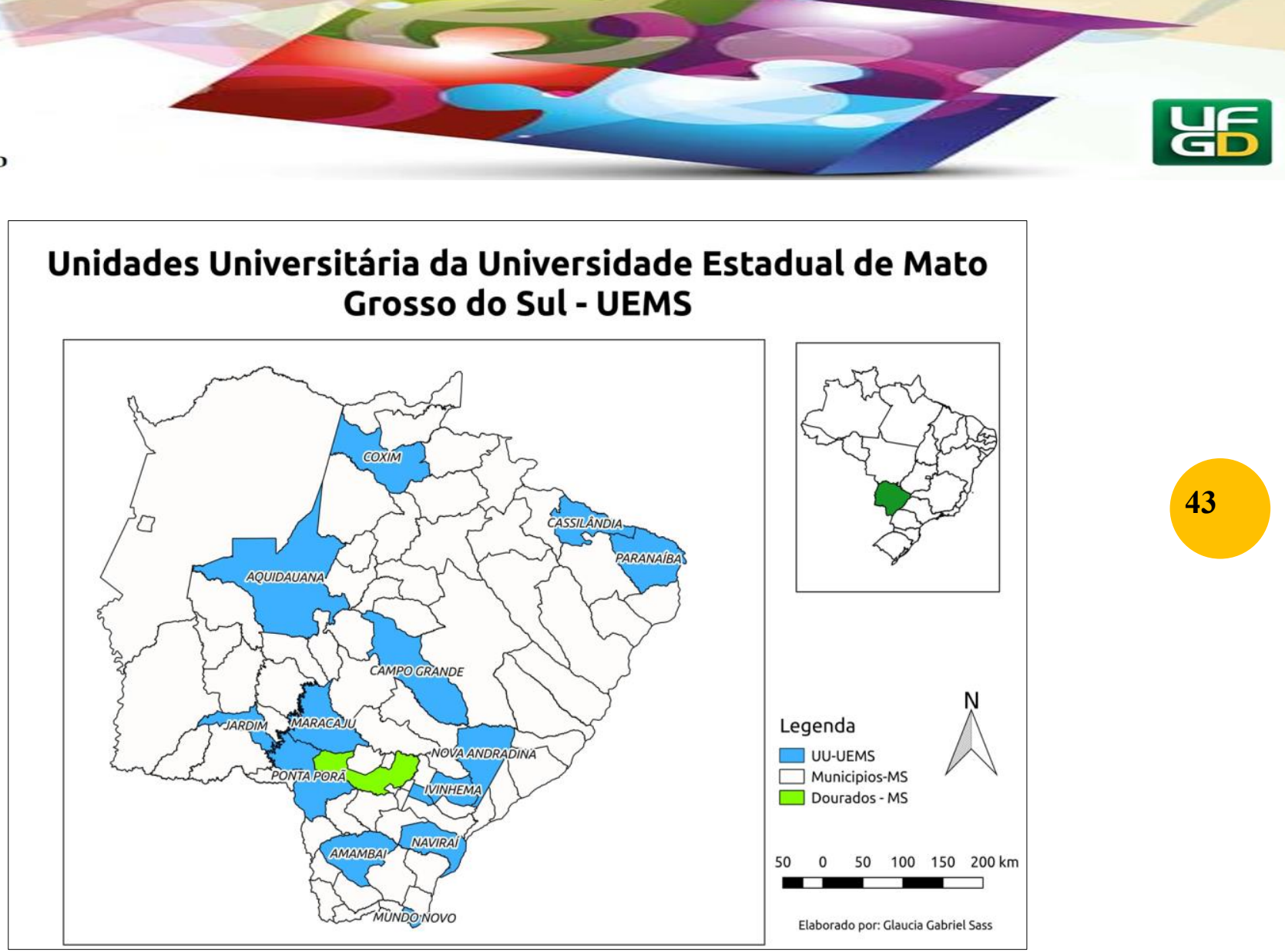

Fonte: Elaborado pelos próprios autores.

Além desses municípios, a UEMS também está inserida em mais outros 7 municípios por meio dos polos de EaD em parceria com a UAB: Água Clara, Aparecida do Taboado, Bela Vista, Camapuã, Japorã, Miranda e Paranhos, Figura 2.

São 22 municípios contemplados atualmente com ações da UEMS objetivando sempre levar a educação superior pública, gratuita e de qualidade para nossa população. Isso em consonância com a nossa missão institucional de

"Gerar e disseminar o conhecimento, com vistas ao desenvolvimento das potencialidades humanas, dos aspectos político, econômico e social do Estado, e com compromisso democrático de acesso à educação superior e o fortalecimento de outros níveis de ensino, contribuindo, dessa forma, para a consolidação da democracia." (UNIVERSIDADE ESTADUAL DE MATO GROSSO DO SUL, 2019).

Figura 2: Polos EaD UEMS em parceria com a UAB em Mato Grosso do Sul. 

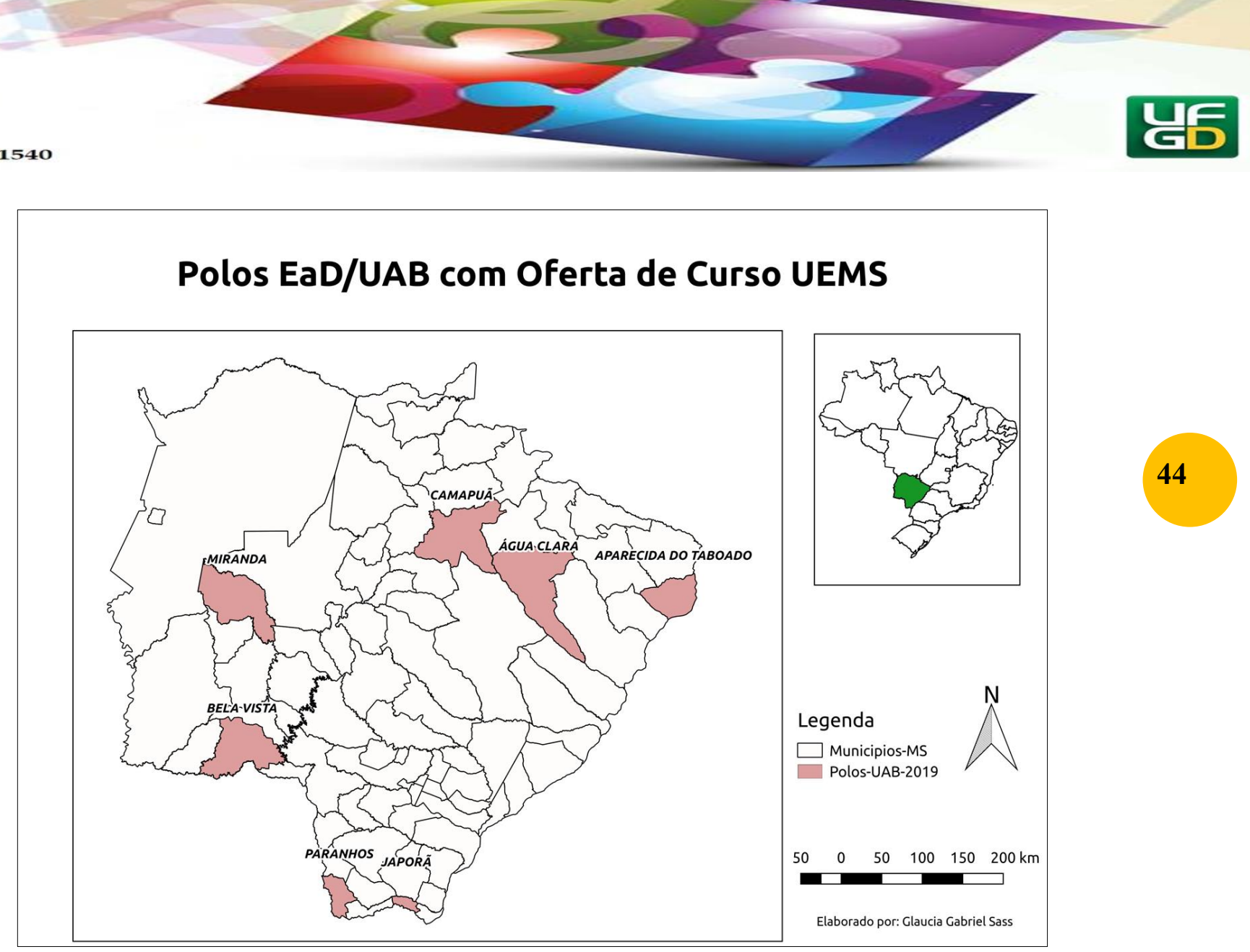

Fonte: Elaborado pelos próprios autores.

\section{A EDUCAÇÃO A DISTÂNCIA NA UEMS.}

A história da Educação a Distância (EaD) na UEMS (EaD/UEMS) tem início no Plano de Desenvolvimento Institucional (PDI) de 2002 - 2007 (Universidade Estadual de Mato Grosso do Sul, 2002). Esse plano orientava que os cursos de graduação deveriam ser presenciais. Somente as atividades de pós-graduação e extensão poderiam ser a distância. Mesmo com essa restrição o PDI coloca a modalidade de ensino a distância em discussão dentro da instituição, em uma de suas metas previa a estratégia de "Promover encontros para discussões relativas à Educação a Distância.”. Algumas outras estratégias do PDI 2002-2007 descreviam:

"Prover de infraestrutura o Núcleo de Educação e Tecnologia com vistas ao desenvolvimento de laboratórios e projetos experimentais em Educação a Distância.”, “Adquirir equipamento e material necessários ao desenvolvimento de projetos, cursos e disciplinas nas modalidades de educação aberta, continuada e a distância.", "Estabelecer intercâmbio com outros organismos institucionais que atuam com Educação a Distância 


\section{HORIZONTES - REVISTA DE EDUCACATO}

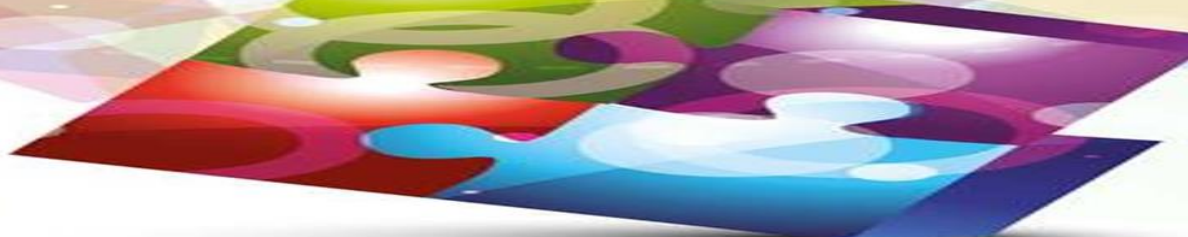

para troca de experiências." e "Produzir Manual de Orientação sobre a forma de trabalhar com novas tecnologias e Educação a Distância."

Essas estratégias, em meio a tantas outras, permitiram iniciar na UEMS as discussões e implantações de políticas e infraestrutura para a EaD de hoje. Em 2002, a UEMS implantou o Núcleo de Educação e Tecnologia (NET), vinculado a Pró-Reitoria de Extensão e Assuntos Comunitários, encarregado de elaborar ações que sensibilizassem a comunidade interna da UEMS. Em novembro de 2007, o NIT passou a ser vinculado a Pró-Reitoria de Ensino (Universidade Estadual de Mato Grosso do Sul, 2008). Esta Pró-Reitoria definiu entre suas metas para este ano de 2008 "Promover discussões sobre a Educação Profisssional e Tecnológica de nível Superior e sobre Educação a Distância;" (UNIVERSIDADE ESTADUAL DE MATO GROSSO DO SUL, 2008).

Ainda em 2008, o novo PDI da Universidade destacava as seguintes atividades desenvolvidas pelo NIT no ano de 2007:

- $\quad$ "Solicitação de credenciamento da UEMS para oferta de educação a distância, via SAPIENs/MEC;

- Elaboração e Apresentação do Projeto do Curso de Especialização em Educação Especial na modalidade a distância para concorrer ao Edital de Seleção Universidade Aberta (UAB) no 01/2006 -SEED/MEC/2006/2007.

- Início dos estudos de avaliação da implantação do software MOODLE, uma ferramenta de aprendizagem em substituição ao TelEduc, ..."

Mesmo que de maneira tímida, em 2008, a UEMS começa a dar seus primeiros passos no Ensino a Distância. Além das atividades citadas anteriormente, no PDI 2008, a seção "VII OFERTA DE EDUCAÇÃO A DISTÂNCIA" relata a concretização das primeiras atividades e apresenta o Quadro 1 com as informações sobre o curso de Licenciatura em Biologia em andamento e o andamento dos processos para a oferta dos outros dois cursos (UNIVERSIDADE ESTADUAL DE MATO GROSSO DO SUL, 2008). Essas ações foram desenvolvidas pelo NIT até o ano de 2008, quando a UEMS passou a contar com uma Assessora em Educação a Distância.

Quadro 1. Ofertas de cursos a distância.

\begin{tabular}{|l|l|l|l|l|}
\hline Cursos & Parcerias & $\begin{array}{l}\text { Coorden } \\
\text { ação }\end{array}$ & $\begin{array}{l}\text { Total } \\
\text { vagas }\end{array}$ & Obs. \\
\hline
\end{tabular}




\section{HORIZONTES - REVISTA DE EDUCACATO}

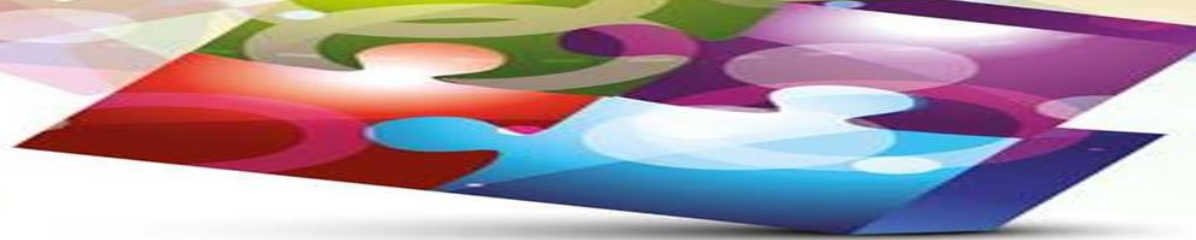

\begin{tabular}{|c|c|c|c|c|c|c|}
\hline Biologia & $\begin{array}{l}\text { Consórcio } \\
\text { Setentrional }\end{array}$ & UFMS & UEMS & $\begin{array}{l}50-\text { Jardim } \\
50-\text { Bela Vista }\end{array}$ & 100 & Em andamento \\
\hline $\begin{array}{l}\text { Tecnologia em Gestão } \\
\text { Pública }\end{array}$ & UEG & UNEMAT & UEMS & $\begin{array}{l}50 \text { - Nova Andradina } \\
50 \text { - Jardim } \\
50 \text { - Ponta Porã } \\
50 \text { - Paranaíba }\end{array}$ & 200 & Previsto \\
\hline $\begin{array}{l}\text { Espec. em Educação } \\
\text { Especial }\end{array}$ & UAB & & UEMS & $\begin{array}{l}40 \text { - Campo Grande } \\
40 \text { - Jardim }\end{array}$ & 80 & Previsto \\
\hline
\end{tabular}

Fonte: (UNIVERSIDADE ESTADUAL DE MATO GROSSO DO SUL, 2008)

Institucionalmente a EaD/UEMS passou a existir quando foi publicada a PORTARIA "P"/UEMS nº 483, de 3 de novembro de 2008, que nomeou uma servidora como Assessora em Educação a Distância, para articular ações entre ensino, pesquisa e extensão. Em 2012, a Assessoria foi oficialmente criada através da PORTARIA UEMS n ${ }^{\circ}$ 031, de 18 de abril de 2012. Esse órgão foi responsável pelo assessoramento e apoio dos órgãos superiores na execução de atividades na área de EaD.

Com a publicação do PDI 2009-2013 a modalidade de ensino a distância começa a ganhar mais espaço e a Pró-Reitoria de Ensino apresenta várias ações prevendo o uso da modalidade com o objetivo de "Melhorar a qualidade do ensino nos Cursos de Graduação" (UNIVERSIDADE ESTADUAL DE MATO GROSSO DO SUL, 2008a). As ações citadas no PDI 2009-2013, são elas, entre outras:

- "Implementação de programa(s) de formação continuada presencial e a distância para a formação pedagógica dos docentes.

- Criação de programa de formação continuada para os coordenadores de curso, por meio de atividades presenciais e a distância.

- Elaboração de propostas curriculares com percentual de carga horária mínima a distância, conforme legislação nacional, de acordo com o interesse, possibilidade e/ou necessidade dos cursos.

- Orientação para elaboração de Projetos Pedagógicos e de planos de ensino que explicitem as estratégias de desenvolvimento das atividades a distância."

O PDI 2009-2013, ainda, cita a Educação a Distância na seção do "Cronograma de Implantação e Desenvolvimento da Instituição para o Período de Vigência do PDI", com a previsão de oferta de cursos pós-graduação lato sensu a distância. Além de citar as melhorias no Ambiente Virtual de Aprendizagem - Moodle e o oferecimento de 20\% da grade curricular 


\section{HORIZONTES - REVISTA DE EDUCACATO}

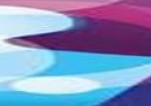

e-ISSN: 2318-1540

na modalidade a distância (desde que previsto no projeto pedagógico) dos cursos presenciais (UNIVERSIDADE ESTADUAL DE MATO GROSSO DO SUL, 2008a).

Os trabalhos desenvolvidos pela Assessora levaram a UEMS a ser credenciada, em 2010, pelo Ministério da Educação (MEC) para a oferta de cursos superiores a distância, por um prazo de 5 anos, em parceria com a Universidade Aberta do Brasil (UAB) (MINISTÉRIO DA EDUCAÇÃO, 2010). Ressalta-se que no término desse credenciamento foi enviado um pedido para recredenciamento da UEMS para oferta de cursos a distância e postado no portal do e-Mec (2015-2016). Em atenção a este pedido, os avaliadores fizeram a visita in loco em março de 2019. Já é de conhecimento que o recredenciamento foi aceito, mas aguarda-se, ainda, o relatório final do Instituto Nacional de Estudos e Pesquisas Educacionais Anísio Teixeira (INEP) com as observações e orientações a serem seguidas pela EaD-UEMS nesse novo período de credenciamento.

A Assessoria de Educação a Distância durante seu período de existência ofereceu alguns cursos em parceria com a UAB, além de promover cursos de capacitação sobre EaD. No ano de 2010 foram oferecidos os cursos de Aperfeiçoamento em Educação Integral e Integrada, nos polos de Água Clara, Camapuã, Costa Rica, Miranda, Porto Murtinho, Rio Brilhante e São Gabriel do Oeste. Ainda em 2010, foi ofertado o curso de Aperfeiçoamento em Diversidade e Cidadania, nos polos de Bataguassu, Costa Rica, Miranda, Porto Murtinho e São Gabriel do Oeste. Esse dois cursos foram os primeiros ofertados na modalidade EaD pela UEMS e tiveram 420 alunos que finalizaram com êxito os dois cursos (DIRETORIA DE EDUCAÇÃO A DISTÂNCIA, 2019a).

Em 2011, a Assessoria de Educação a Distância em conjunto com a UAB, ofereceu dois cursos vinculados ao Programa Nacional de Formação em Administração Pública (PNAP) e em parceria com UAB. São eles o curso de pós-graduação lato sensu em Gestão Pública Municipal, ofertado em três polos da UAB: Água Clara, Camapuã e Miranda, com 114 concluintes. Somado a pós-graduação, foi oferecida a primeira graduação na modalidade EaD da UEMS, o curso de Bacharelado em Administração Pública nos mesmos polos com 97 formandos (DIRETORIA DE EDUCAÇÃO A DISTÂNCIA, 2019a). Esse trabalho, realizado em parceria com a UAB, iniciou a oferta das graduações e pós-graduações na modalidade de ensino a distância. Destaca-se que a parceria com a UAB na UEMS permitiu a implantação desses cursos por meio do fomento recebido e permitiu que a EaD-UEMS fosse sendo difundida. 


\section{HORIZONTES - REVISTA DE EDUCACATO}

$<$

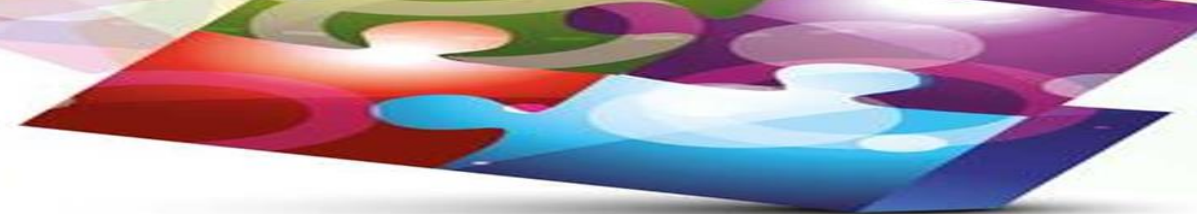

No PDI 2014-2018 a Educação a Distância no âmbito da UEMS começa a ganhar destaque sendo criado um eixo temático de Educação a Distância com objetivos e metas (UNIVERSIDADE ESTADUAL DE MATO GROSSO DO SUL, 2014). A Figura 3 mostra o Objetivo 6 dentro das "Políticas e Programas de Ensino de Graduação" do PDI 2014-2018. Destacando quatro importantes metas para o crescimento da EaD/UEMS.

Figura 3: Eixo Temático: Educação a Distância - PDI 2014-2018

\section{Eixo Temático: Educação a Distância}

\section{Objetivo 6. Institucionalizar a Educação a Distância na UEMS.}

Meta 1. Criar um plano institucional para a EaD.

Meta 2. Dotar as Unidades Universitárias de infraestrutura necessária para oferta de cursos na modalidade EaD.

Meta 3. Capacitar recursos humanos para desenvolver as ações em EaD.

Meta 4. Lotar servidores para atuar nos cursos de EaD.

\begin{tabular}{|l|c|c|c|c|c|}
\hline Período de implantação das ações & 2014 & 2015 & 2016 & 2017 & 2018 \\
\hline
\end{tabular}

Fonte: (UNIVERSIDADE ESTADUAL DE MATO GROSSO DO SUL, 2014).

Em 2015 a RESOLUÇÃO COUNI-UEMS Nº 464, de 25 de setembro de 2015, cria a Diretoria de Educação a Distância (DED) da UEMS (DED/UEMS). Essa resolução foi revogada pela

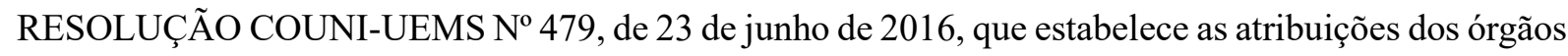
executivos e dos órgãos de assessoramento e apoio dos órgãos executivos superiores da UEMS, incluindo a DED/UEMS.

A DED/UEMS é o "órgão responsável pela superintendência, orientação, coordenação, planejamento, acompanhamento e avaliação das atividades de educação a distância dos cursos de graduação e pós-graduação e demais atividades da UEMS" (UNIVERSIDADE ESTADUAL DE MATO GROSSO DO SUL, 2016). Todo o trabalho desenvolvido de 2010 a 2015 resultou na experiência e capacitação dos servidores e só foi possível por meio da parceria com a UAB. O trabalho da Assessoria de Educação a Distância mostrou para os gestores que era possível oferecer ensino a distância público, gratuito e de qualidade, o que levou a Assessoria ao status de Diretoria.

A missão da DED/UEMS é

"ampliar, na esfera pública, as oportunidades de acesso a educação superior priorizando o estado de Mato Grosso do Sul, por meio das tecnologias de comunicação e informação no sentido de promover uma aprendizagem significativa culturalmente para a formação de pessoas críticas e autônomas que possam colaborar 


\section{HORIZONTES - REVISTA DE EDUCACATO}

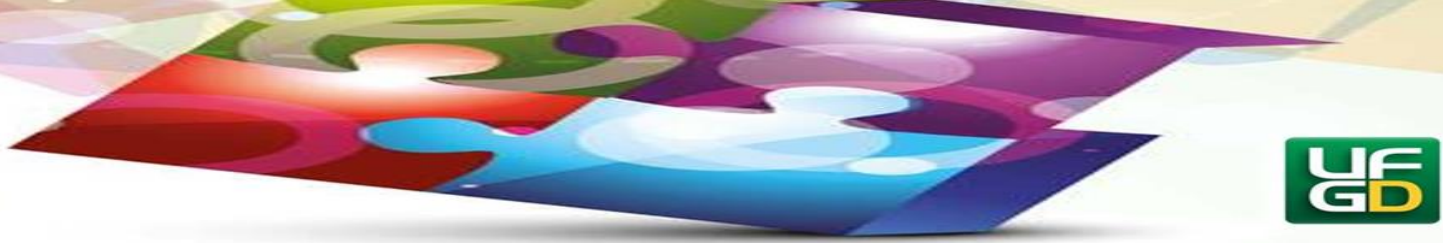

na construção de um estado mais democrático" (DIRETORIA DE EDUCAÇÃO A DISTÂNCIA, 2019b)

Continuando suas atividades, no ano de 2015, a DED/UEMS ofereceu 225 vagas para o curso de Bacharelado em Administração Pública pelo Edital PROE/AEAD/UAB-UEMS $\mathrm{n}^{\mathrm{o}} 11 / 2014$ em parceria com a UAB. Os polos atendidos foram Água Clara, Bela Vista, Camapuã e Miranda, com início das aulas em fevereiro de 2015 (UNIVERSIDADE ESTADUAL DE MATO GROSSO DO SUL, 2015).

Nesse ano também foram ofertados os cursos de pós-graduação Lato Sensu em Educação Especial (polos Bataguassu, Bela Vista, Camapuã, Miranda, São Gabriel do Oeste), Gestão Pública e Gestão em Saúde, esses dois últimos nos polos de Água Clara, Camapuã e Miranda, em um total de 550 vagas (UNIVERSIDADE ESTADUAL DE MATO GROSSO DO SUL, 2015).

Em 2017 a Educação a Distância se fortalece dentro da UEMS com a publicação da RESOLUÇÃO CEPE-UEMS No 1.881, de 21 de junho de 2017, que "Aprova o Regulamento da Educação a Distância no âmbito da Universidade Estadual de Mato Grosso do Sul (UEMS)”. Um momento importante de reconhecimento das ações até então desenvolvidos pela Assessoria e depois pela DED/UEMS (UNIVERSIDADE ESTADUAL DE MATO GROSSO DO SUL, 2017).

Em 2018, pelo Edital 75/2014 CAPES/UAB, foram ofertados os cursos apresentados no quadro 2. A Figura 3 apresentou a distribuição dos polos $\mathrm{EaD} / \mathrm{UAB}$ onde esses cursos estão sendo ofertados. Atualmente, 2019, estamos no segundo ano dos cursos e realizando as reofertas das disciplinas do primeiro ano para os alunos que não conseguiram concluí-las.

Quadro 2: Cursos oferecidos pela UEMS em convênio com a UAB, iniciados em 2018.

\begin{tabular}{|l|l|l|l|}
\hline \multicolumn{1}{|c|}{ Bacharelado } & \multicolumn{2}{c|}{ Licenciatura } & \multicolumn{1}{c|}{ Especialização } \\
\hline \multicolumn{1}{|c|}{ Administração Pública } & \multicolumn{1}{|c|}{ Pedagogia } & \multicolumn{1}{c|}{ Ciências Sociais } & \multicolumn{1}{c|}{ Gestão Pública } \\
\hline Aparecida do Taboado & Aparecida do Taboado & Água Clara & Aparecida do Taboado \\
\hline Japorã & Paranhos & Bela Vista & Japorã \\
\hline Paranhos & & Camapuã & Paranhos \\
\hline & & Japorã & \\
\hline & & Miranda & \\
\hline
\end{tabular}

Fonte: Elaborado pelos próprios autores.

No período de 2008 a 2018 a EaD/UEMS esteve presente em em 16 municípios, Quadro 3, sendo que em 5 desses possuem UU além dos polos EaD/UAB. Esse trabalho mostra o comprometimento da UEMS em interiorizar o ensino e as oportunidades de estudo para a 


\section{HORIZONTES - REVISTA DE EDUCAÇÃO}

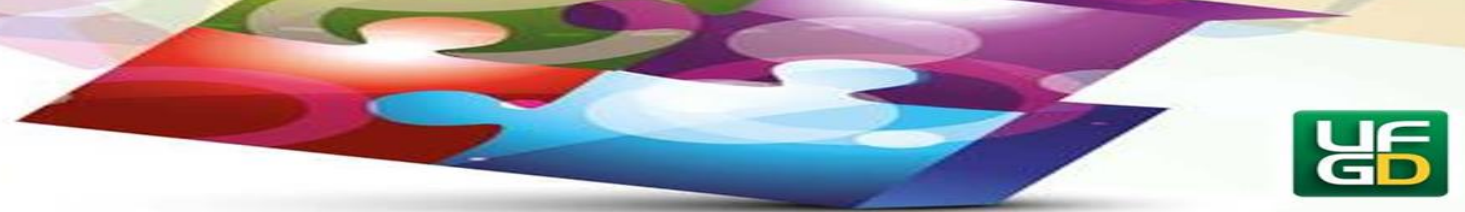

população sul-mato-grossense. Considerando os 15 municípios com UU mais os 11 polos

EaD/UAB, a UEMS se fez presente em 26 municípios do estado, um total de $35 \%$.

Quadro 3: Cursos oferecidos pela UEMS em convênio com a UAB.

\begin{tabular}{|c|c|}
\hline Município & Curso \\
\hline Água Clara & $\begin{array}{l}\text { Aperfeiçoamento em Educação Integral e Integrada } \\
\text { Lato sensu em Gestão Pública Municipal } \\
\text { Bacharelado em Administração Pública } \\
\text { lato sensu Gestão Pública } \\
\text { lato sensu Gestão em Saúde } \\
\text { Licenciatura em Ciências Sociais }\end{array}$ \\
\hline Aparecida do Taboado & $\begin{array}{l}\text { Bacharelado em Administração Pública } \\
\text { Licenciatura em Pedagogia }\end{array}$ \\
\hline Bataguassu & $\begin{array}{l}\text { Aperfeiçoamento em Diversidade e Cidadania } \\
\text { Lato Sensu em Educação Especial }\end{array}$ \\
\hline Bela vista & $\begin{array}{l}\text { Licenciatura Biologia } \\
\text { Bacharelado em Administração Pública } \\
\text { Lato Sensu em Educação Especial } \\
\text { Licenciatura em Ciências Sociais }\end{array}$ \\
\hline Camapuã & $\begin{array}{l}\text { Aperfeiçoamento em Educação Integral e Integrada } \\
\text { Lato sensu em Gestão Pública Municipal } \\
\text { Bacharelado em Administração Pública } \\
\text { Lato Sensu em Educação Especial } \\
\text { Lato sensu Gestão Pública } \\
\text { Lato sensu Gestão em Saúde } \\
\text { Licenciatura em Ciências Sociais }\end{array}$ \\
\hline Costa Rica & $\begin{array}{l}\text { Aperfeiçoamento em Educação Integral e Integrada } \\
\text { Aperfeiçoamento em Diversidade e Cidadania }\end{array}$ \\
\hline Japorã & $\begin{array}{l}\text { Bacharelado em Administração Pública } \\
\text { Lato sensu Gestão Pública } \\
\text { Licenciatura em Ciências Sociais }\end{array}$ \\
\hline Jardim - UU $\mathrm{UU}^{3}$ & Licenciatura Biologia \\
\hline Miranda & $\begin{array}{l}\text { Aperfeiçoamento em Educação Integral e Integrada } \\
\text { Aperfeiçoamento em Diversidade e Cidadania } \\
\text { Lato sensu em Gestão Pública Municipal } \\
\text { Bacharelado em Administração Pública } \\
\text { Lato Sensu em Educação Especial } \\
\text { Lato sensu Gestão Pública } \\
\text { Lato sensu Gestão em Saúde } \\
\text { Licenciatura em Ciências Sociais }\end{array}$ \\
\hline Paranhos & $\begin{array}{l}\text { Bacharelado em Administração Pública } \\
\text { Licenciatura em Pedagogia } \\
\text { Lato sensu Gestão Pública }\end{array}$ \\
\hline Porto Murtinho & $\begin{array}{l}\text { Aperfeiçoamento em Educação Integral e Integrada } \\
\text { Aperfeiçoamento em Diversidade e Cidadania }\end{array}$ \\
\hline Rio Brilhante & Aperfeiçoamento em Educação Integral e Integrada \\
\hline
\end{tabular}




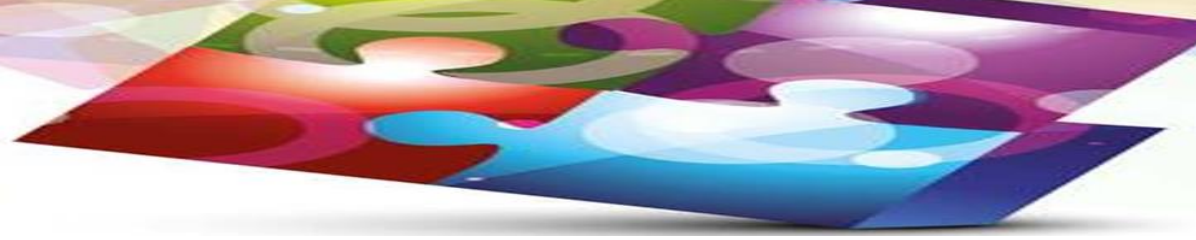

São Gabriel do Oeste Aperfeiçoamento em Educação Integral e Integrada Aperfeiçoamento em Diversidade e Cidadania Lato Sensu em Educação Especial

Fonte: Elaborado pelos próprios autores.

A presença da EaD/UEMS nesses 12 municípios mostra o esforço dos que trabalham para levar a educação superior ao interior do estado também. O gráfico da Figura 4 apresenta a quantidade de cursos oferecidos em cada municípios, cursos de aperfeiçoamento, graduação e Latu Sensu. Chamo a atenção para esse gráfico no que diz respeito aos pequenos municípios que foram atendidos e estão sendo atendidos, como é o caso de Japorã.

Figura 4: Gráfico com os municípios atendidos pela EaD/UEMS, entre 2008 e 2019.

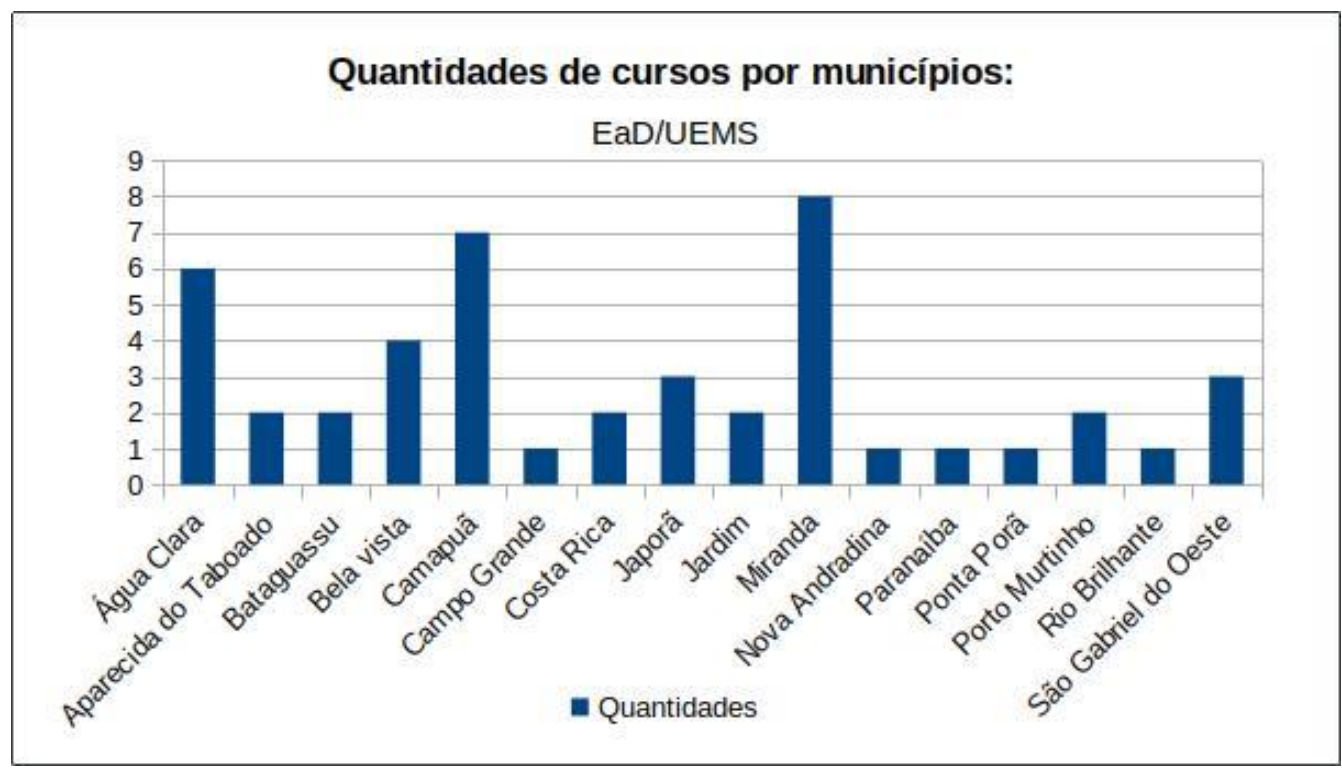

Fonte: Elaborado pelos próprios autores.

Durante o período de atuação, 2010 a 2018, a EaD/UEMS certificou 420 alunos com aperfeiçoamento, 173 graduação e 909 pós-graduados. Os dados sobre os concluintes dos cursos apresentados no Quadro 1, de 2008, não foram resgatados, apesar do empenho dos autores.

Figura 5: Gráfico com o total de alunos concluintes pelo tipo de curso. 

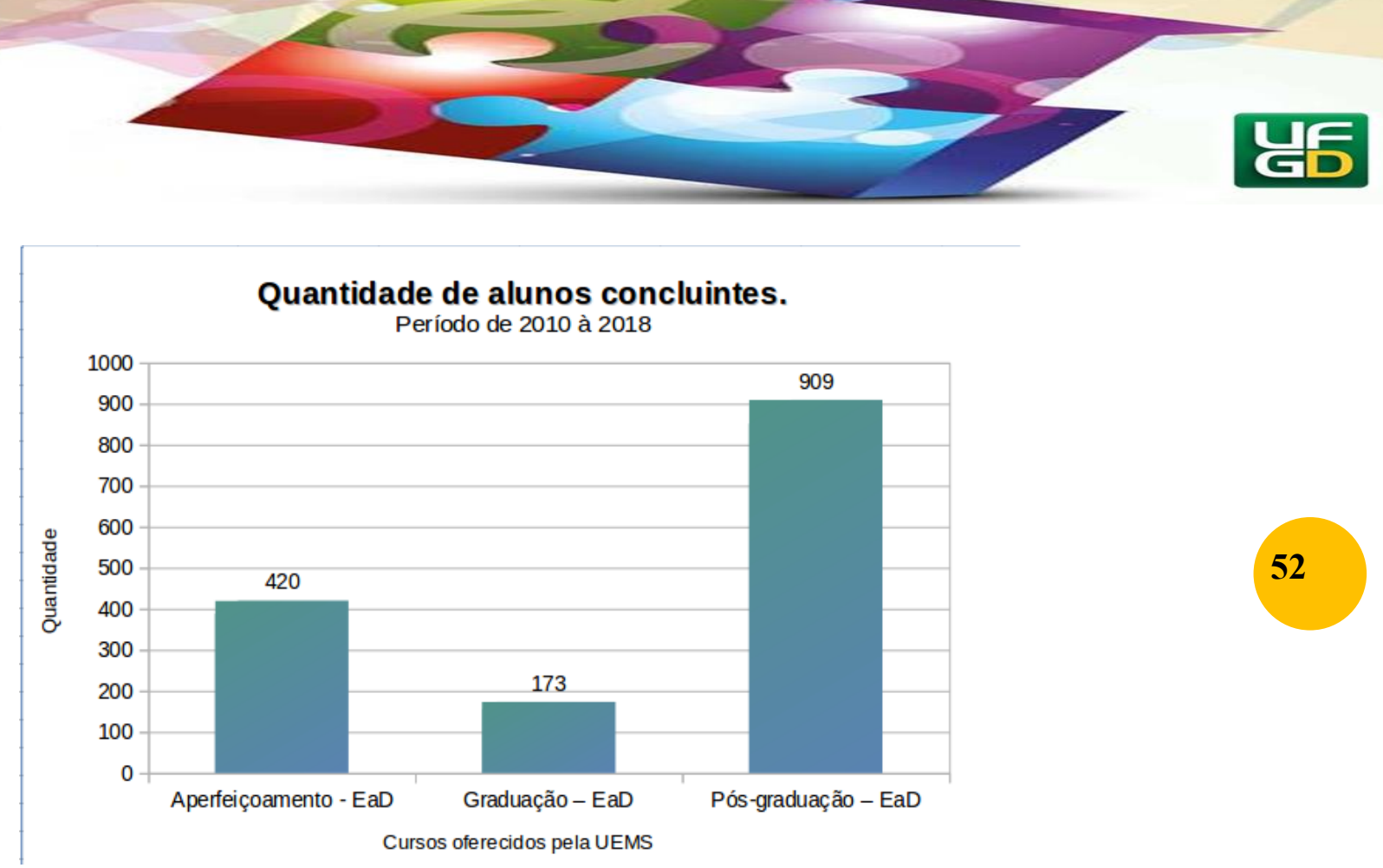

Fonte: Elaborado pelos próprios autores.

Além dos alunos na modalidade de ensino a distância a EaD/UEMS atende também os alunos das graduações na modalidade presencial. Os dados coletados em dezembro de 2018 estão representados no gráfico da Figura 6. Nesse gráfico são apresentados a quantidade de alunos cadastrados no AVA - Moodle por UU.

Figura 6: Uso dos recursos da EaD pelos alunos dos cursos de graduação presenciais da UEMS.

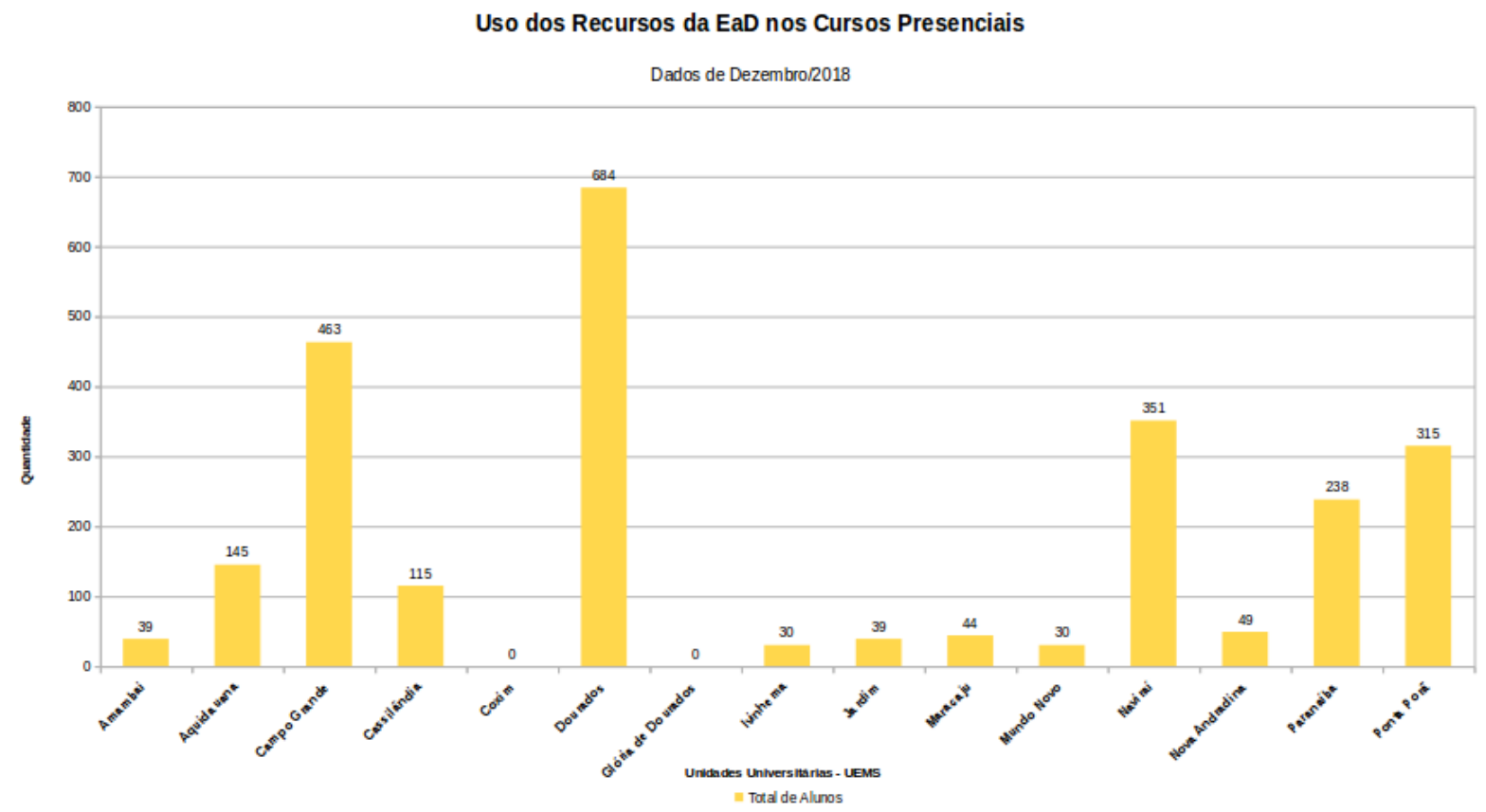




\section{HORIZONTES - REVISTA DE EDUCACATO}

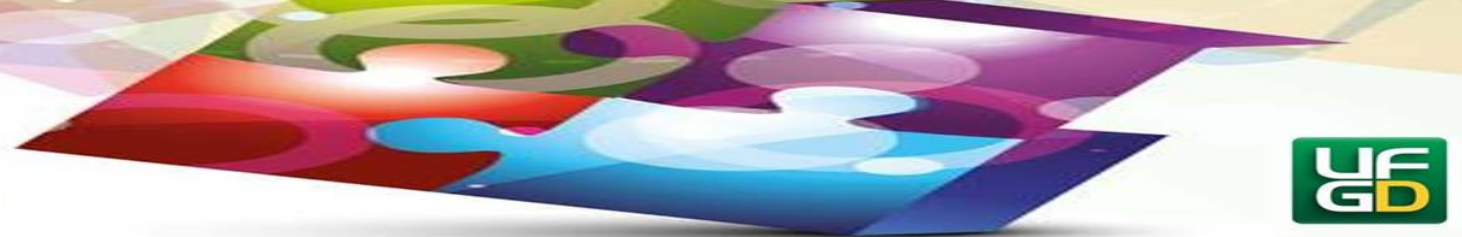

Fonte: Elaborado pelos próprios autores.

\section{CONSIDERAÇÕES FINAIS}

Como foi visto, até o presente momento, a história da $\mathrm{EaD}$ na UEMS se confunde com a história e o fomento da UAB. No entanto, desde 2018 a Universidade tem buscado a efetiva institucionalização da modalidade. O objetivo, inicialmente, é transformar em polos de $\mathrm{EaD}$ as Unidades Universitárias, que além de oferecerem os cursos presenciais poderiam ofertar cursos a distância tanto de graduação, pós-graduação e extensão. Além dessa ação, a UEMS tem sido acionada por diversas prefeituras de municípios onde não há ofertas de cursos superiores para o oferecimento de cursos específicos para a demanda de tais municípios.

Com a institucionalização e com a ampliação de ofertas para as UU e municípios conveniados, a EaD da UEMS contribuirá para cumprir, cada vez mais, a missão da Universidade democratizando o acesso à educação e ajudando no desenvolvimento de potencialidades humanas no estado de Mato Grosso do Sul. O caminho ainda é longo e as dificuldades são muitas, mas a cada ação realizada busca-se o fortalecimento de outros níveis de ensino e a consolidação da democracia.

\section{REFERÊNCIAS}

DIRETORIA DE EDUCAÇÃO A DISTÂNCIA - DED/UEMS. A Diretoria de Educação a Distância. Dourados, 2019b. [acesso em: 5 de jul 2019] Disponível em: http://www.uems.br/ead/menu/4d0384f7ee5bec5309ebf012f47b6f9a.

DIRETORIA DE EDUCAÇÃO A DISTÂNCIA - DED/UEMS. Indicadores das Ofertas de Cursos a Distância UEMS-UAB. Dourados, 2019a. [acesso em: 1 de jul 2019] Disponível em: http://www.uems.br/ead/menu/4d0384f7ee5bec5309ebf012f47b6f9a.

MATO GROSSO DO SUL (Estado). Constituição Estadual de Mato Grosso do Sul. Campo Grande, 1979.

MATO GROSSO DO SUL (Estado). Constituição Estadual de Mato Grosso do Sul. Campo Grande, 1989. [acesso em: 1 de jul 2019] Disponível em: http://aacpdappls.net.ms.gov.br/appls/legislacao/secoge/govato.nsf/0a67c456bc566b8a04257 e590063flfd/dfde24a4767ddcbf04257e4b006c0233?OpenDocument.

MATO GROSSO DO SUL (Estado). Decreto Estadual n. 7,585, de 22 de dezembro de 1993. Institui a Universidade Estadual de Mato Grosso do Sul, com sede e foro na cidade de Dourados, e dá outras providências. [acesso em: 1 de jul 2019] Disponível em: 


\section{MORIZONTES - REVISTA DE EDUCACATO}

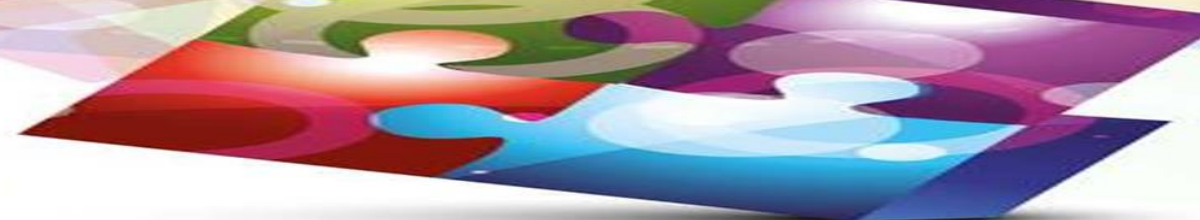

http://aacpdappls.net.ms.gov.br/appls/legislacao/secoge/govato.nsf/fd8600de8a55c $7 f c 04256 b$ 210079ce25/e1aed50e005a4ed604256e2d006986dd?OpenDocument

MATO GROSSO DO SUL (Estado). Lei Estadual n. 1.461, de 20 de dezembro de 1993. Autoriza o Poder Executivo a instituir a Fundação Universidade Estadual de Mato Grosso do Sul. [acesso em: 1 de jul 2019] Disponível em: http://aacpdappls.net.ms.gov.br/appls/legislacao/secoge/govato.nsf/448b683bce4ca 84704256 c0b00651e9d/1d862dc974bec2de04256e450002eae3?OpenDocument

MATO GROSSO DO SUL (Estado). Lei Estadual n. 533, de 12 de março de 1985. Autoriza o Poder Executivo a instalar a Universidade Estadual de Mato Grosso do Sul, com sede em Dourados. [acesso em: 1 de jul 2019] Disponível em: http://aacpdappls.net.ms.gov.br/appls/legislacao/secoge/govato.nsf/448b683bce4ca84704256 c0b00651e9d/fc6ac2486ad77d4e04256e450002e91c?OpenDocument.

MINISTÉRIO DA EDUCAÇÃO (MEC). PORTARIA NORMATIVA No 1.369, DE 07 DE DEZEMBRO DE 2010. Credencias Instituições Públicas de Educação Superior e Polos de Apoio Presencial. [acesso em: 1 de jul 2019] Disponível em: https://edutec.unesp.br/images/stories/portarias/portaria\%20normativa\%201369\%20dia\%200 7-12-2010.pdf

UNIVERSIDADE ESTADUAL DE MATO GROSSO DO SUL - UEMS. História \& Missão. Dourados, 2019a. [acesso em: 1 de jul 2019] Disponível em: http://www.uems.br/historia.

UNIVERSIDADE ESTADUAL DE MATO GROSSO DO SUL - UEMS. Plano de Desenvolvimento Institucional 2002 - 2007. In: MAGRIN, A . G. E.; Henrique Jorge FERNANDES, H. J.; SOARES, M. R. (Org.). Dourados, 2002. [acesso em: 1 de jul 2019] Disponível em: http://www.uems.br/pdi/assets/arquivos/pdi-2002-2007.pdf

UNIVERSIDADE ESTADUAL DE MATO GROSSO DO SUL - UEMS. Plano de Desenvolvimento Institucional 2008. In: Divisão de Planejamento e Avaliação Institucional DPAI /PROAP/UEMS (Org.). Dourados, 2008. [acesso em: 1 de jul 2019] Disponível em: http://www.uems.br/pdi/assets/arquivos/pdi-2008.pdf

UNIVERSIDADE ESTADUAL DE MATO GROSSO DO SUL - UEMS. Plano de Desenvolvimento Institucional 2009-2013. In: Comissão Institucional - PDI e Divisão de Planejamento e Avaliação Institucional - DPAI (Org.). Dourados, 2008a. [acesso em: 1 de jul 2019] Disponível em: http://www.uems.br/assets/uploads/proap/planejamento/1_2018-0608_15-00-22.pdf

UNIVERSIDADE ESTADUAL DE MATO GROSSO DO SUL - UEMS. Plano de Desenvolvimento Institucional 2014-2018. In: Pró-Reitoria de Administração e Planejamento (PROAP) e Divisão de Planejamento e Avaliação Institucional (DPAI) (Org.). Dourados, 2014. [acesso em: 1 de jul 2019] Disponível em: http://http://www.uems.br/assets/uploads/proap/planejamento/1_2018-06-08_15-01-47.pdf UNIVERSIDADE ESTADUAL DE MATO GROSSO DO SUL - UEMS. Relatório Anual de Atividades - 2013. In: Divisão de Planejamento e Avaliação Institucional - DPAI (Org.). Dourados, 2013. [acesso em: 1 de jul 2019] Disponível em: http://www.uems.br/assets/uploads/proap/planejamento/1_2014-06-27_13-31-04.pdf 


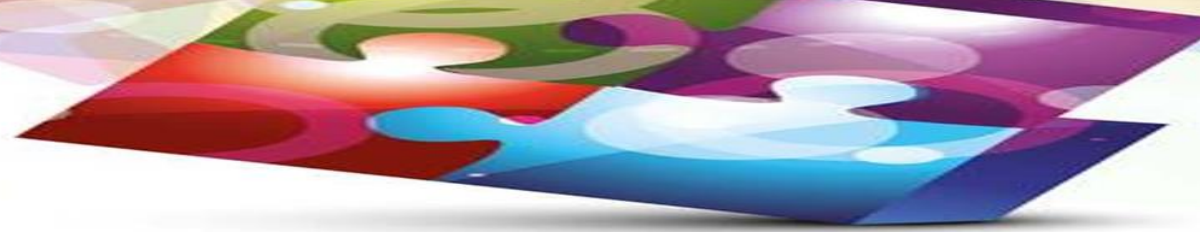

UNIVERSIDADE ESTADUAL DE MATO GROSSO DO SUL - UEMS. Relatório Anual de Atividades - 2015. In: Divisão de Planejamento e Avaliação Institucional - DPAI (Org.). Dourados, 2015. [acesso em: 1 de jul 2019] Disponível em: http://www.uems.br/assets/uploads/proap/planejamento/2_2018-06-08_12-29-39.pdf

UNIVERSIDADE ESTADUAL DE MATO GROSSO DO SUL - UEMS. RESOLUÇÃO CEPE-UEMS No 1.881, de 21 de junho de 2017. Dourados, 2017. [acesso em: 5 de jul 2019] Disponível em: http://www.uems.br/assets/uploads/ailen/arquivos/2017-07-18_12-52-12.pdf UNIVERSIDADE ESTADUAL DE MATO GROSSO DO SUL - UEMS. RESOLUÇÃO COUNI-UEMS N $N^{o}$ 479, de 23 de junho de 2016.. Dourados, 2016. [acesso em: 5 de jul 2019] Disponível em: http://www.uems.br/assets/uploads/ailen/arquivos/2016-07-20_09-11-54.pdf

Data do envio do trabalho: 19/10/2019

Aprovado em: 29/10/2019

Publicado em: 18/12/2019 